\title{
An uncommon presentation of cystic pachypleuritis successfully treated by uniportal VATS-case report
}

\author{
Marco Chiappetta ${ }^{1,2}$, Dania Nachira ${ }^{1,2}$, Maria Teresa Congedo ${ }^{1,2}$, Gian Maria Ferretti ${ }^{1,2}$, Amedeo Iaffaldano ${ }^{1,2}$, \\ Leonardo Petracca Ciavarella ${ }^{1,2}$, Elisa Meacci $^{1,2}$, Stefano Margaritora ${ }^{1,2}$ \\ ${ }^{1}$ Department of Thoracic Surgery, Fondazione Policlinico Universitario A. Gemelli IRCCS, Roma, Italy; ${ }^{2}$ Department of Thoracic Surgery, \\ Università cattolica del Sacro Cuore, Roma, Italy \\ Correspondence to: Marco Chiappetta, MD. Department of Thoracic Surgery, Fondazione Policlinico Universitario A. Gemelli IRCCS, Roma, Italy. \\ Email: marco_chiappetta@yahoo.it; marcokiaps@hotmail.it.
}

\begin{abstract}
We herein report the uncommon presentation of a cystic pleuritis affecting a young woman. The patient presented chronic and continuous right posterior interscapular pain, so a chest X-ray detected an apical superior mass confirmed at the computed tomography. In particular, it was $8 \times 6.5$ centimeters, occupying the right apex with compression on the right upper lobe, also if it was difficult to determinate if it originated form the lung or from the pleura. Considering the dimension and the presence of symptoms, surgery was indicated performing an uniportal video assisted thoracic surgery (VATS) approach to investigate the nature and to provide to the resection. Intraoperatively, the mass presented a smooth hyaline surface and had a large implant on the parietal pleura, completely covering the apex, while a small tenacious region of contact with the lung parenchyma was present. So, after a small wedge resection and aspiration of the fluid content, obtaining more operative space and easier mobilization of the mass, a complete resection was possible through an uniportal access, despite the initial dimension and rigidity. The histologic exam described the presence of a chronic cystic pleuritis, un uncommon pleural disease that in this case was characterized by a single giant symptomatic pleural cyst, successfully treated using an uniportal VATS approach. We present the following case in accordance with the CARE guideline.
\end{abstract}

Keywords: Uniportal video assisted thoracic surgery (uniportal VATS); pleuritis; pleura

Received: 14 August 2019; Accepted: 14 November 2019; Published: 26 November 2019.

doi: $10.21037 /$ shc.2019.11.04

View this article at: http://dx.doi.org/10.21037/shc.2019.11.04

A 37 years old woman was referred to our division of thoracic surgery for the recent diagnosis of a thoracic mass detected at a chest X-ray done for the occurrence of interscapular persistent pain.

In particular, the chest computed tomography confirmed the presence of a thoracic mass located in the apex of the right pleural cavity in the sub-clavicular region, with straight contact with the first three ribs without signs of infiltration. The mass had regular rounded, margin and raised the dimension of $8 \times 6.5$ centimeters, the internal region presented the value of 10 Hounsfield unit $(\mathrm{HU})$ and the margin had a discrete contrast enhancement.

Moreover, part of the upper lobe parenchyma was compressed, but it was difficult to discriminate the exact origin (pleural or pulmonary) and the nature of the mass, also if the characteristics suggested the cystic and benign nature, also if it was symptomatic for pain.

For this reason, after the personal history and the blood test analysis excluded the presence of active or recent infective pathology, the resection of the mass was indicated.

\section{Surgery}

Surgery was indicated using a uniportal video assisted thoracic surgery (VATS) approach as described by Dr. Gonzalez-Rivas (1), so a single port incision of 4 centimeters was performed at the fourth intercostal space between the mid-axillary and the posterior axillary line, preserving the 


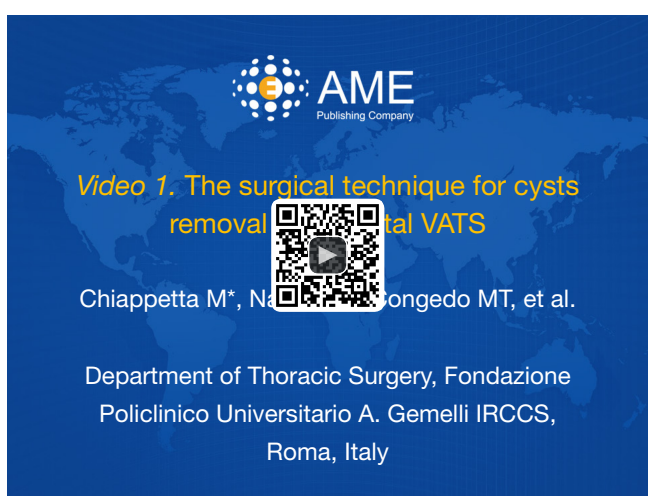

Figure 1 The surgical technique for cysts removal in uniportal VATS (2). The crucial points are underlined: firstly, the wedge resection to free the lung parenchyma and obtain space for a safe operation. Secondly, the detention of the cysts by aspiration of its content that permitted an easier mobilization and dissection. Finally, the use of an energy device that permitted a rapid dissection and an effective hemostasis. VATS, video assisted thoracic surgery.

Available online: http://www.asvide.com/watch/33006

latissimus dorsi and progressing with a muscle sparring incision on the serratus anterior muscle. The right lung was completely excluded using a double lumen oro-tracheal tube, with single ventilation on the left lung. A 30 degrees/ 10 millimeters camera and a wound protector were used.

The pleural mass was easily detected, and it presented a free thick surface suggesting a fibrous nature, but it also presented a large contact area with the chest wall apex and a little region of contact with the lung apex (Figure 1). Moreover, it had a very tense surface, due its hydric content, determining a very low mobility.

The first step to start the resection was to obtain the complete exposure of the mass, so, considering the tenacious adherence of the mass with a small region of the lung parenchyma, a small parenchymal resection was needed, and in particular it was performed using a 45 millimeters stapler.

In this way it was possible to free the lung and earn space for the following maneuvers. Then the dissection of the mass was conducted identifying the correct plane between the capsule of the mass and the chest wall, also using the aspirator as a blunt dissector for its curvature angle that permitted to perform these passages in an easier manner.

Conversely, the presence of tension on the mass surface reduced the mobilization, and the tension associated to the smooth surface avoided the possibility to grab the mass and obtain the space to complete the dissection around it.

For these reasons, it was needed to incise the cyst and suck its content, decreasing the tension and improving its mobilization. After this simple maneuver, it was possible to proceed to the mass dissection with a better view also to avoid nerve and vascular damages. In particular, traction was performed using an instrument that permitted to grab the cyst maintaining the hole closed to avoid fluid dispersion. Because dissection was performed in the vascularized extrapleural space and next to the superior cava vein, we preferred to continue it using bipolar forceps and energy device (Harmonic Ace ${ }^{\circledR}$-Ethicon).

Postoperative (p.o.) period was regular, the chest tube was removed in II p.o. day and the patient was discharged in III p.o. day.

The histologic exam showed the presence of chronic cystic pachypleuritis.

At 1 year of follow up the patients is in excel clinical condition and the pain symptomatology is completely solved.

\section{Discussion}

Cystic lesion of the pleural cavity is quite rare, and usually referred to bronchogenic or pericardial cyst $(3,4)$. We reported an uncommon case of pleuritis, presented as a cystic lesion without reabsorption of the intralesional fluid after the acute phase. Another interesting finding regarded the evolution of this pathology, without effusion in the thoracic cavity but with creation of a separate camera at the level of the parietal pleura.

The reason of this phenomenon remains uncertain, but a possible explanation may be due the location and the effectiveness of the pleural lymphatic system that is responsible of the reabsorption of the pleural effusion.

Indeed, the major part of the pleural drainage system is located in the postero-basal area $(5,6)$, so an inflammatory process with effusion formation in the apex of the thorax may become chronic without fluid or pleural thickness resolution (7).

In this case, surgical intervention was proposed to obtain a diagnosis and, as well as possible, to perform a definitive therapy especially for the retro-scapular pain. A uniportal VATS approach may presents some difficulties, but it also present excellent results in term of effectiveness, aesthetic results and patient management (1).

The major difficulty regarded the very small space for operation and instrument management, considering the sticky adhesion between the lung and the parietal pleura or 
the tension of the fluid inside the pleura. In this case, the firs fundamental step was to earn space, also for the needed of performing the intervention in a safe way.

We use two little tricks, the first performing a little wedge resection of the apex of the lung to free the rest of the parenchyma from the pleura, the second was to suck the cyst's fluid to decrease the pleural surface tension and permit to crab and remove the thickened pleura. Finally, the use of an energy device was very comfortable, for the possibility to use a single instrument for dissection and coagulation, earning space and time.

\section{Conclusions}

We reported an uncommon case of pleural cyst occurred after apex pleuritis, surgically treated with excellent results by uniportal VATS, suggesting that also this kind of pathology may be treated with this type of surgical technique.

\section{Acknowledgments}

Funding: None.

\section{Footnote}

Provenance and Peer Review: This article was commissioned by the editorial office, Shanghai Chest for the series "The Second Roman Tips and Tricks in Thoracic Surgery the Great Potential of Uniportal VATS". The article has undergone external peer review.

Conflicts of Interest: All authors have completed the ICMJE uniform disclosure form (available at http://dx.doi. org/10.21037/shc.2019.11.04). The series "The Second Roman Tips and Tricks in Thoracic Surgery - the Great Potential of Uniportal VATS" was commissioned by the editorial office without any funding or sponsorship. EM served as the unpaid Guest Editor of the series and serves as an unpaid editorial board member of Shanghai Chest from Mar 2018 to Feb 2020. SM served as the unpaid Guest Editor of the series. The authors have no other conflicts of interest to declare.

Ethical Statement: The authors are accountable for all aspects of the work in ensuring that questions related to the accuracy or integrity of any part of the work are appropriately investigated and resolved. All procedures performed in studies involving human participants were in accordance with the ethical standards of the institutional and/or national research committee(s) and with the Helsinki Declaration (as revised in 2013). Written informed consent was obtained from the patient for publication of this Case Report and any accompanying images.

Open Access Statement: This is an Open Access article distributed in accordance with the Creative Commons Attribution-NonCommercial-NoDerivs 4.0 International License (CC BY-NC-ND 4.0), which permits the noncommercial replication and distribution of the article with the strict proviso that no changes or edits are made and the original work is properly cited (including links to both the formal publication through the relevant DOI and the license). See: https://creativecommons.org/licenses/by-nc-nd/4.0/.

\section{References}

1. Gonzalez-Rivas D, Paradela M, Fernandez R, et al. Uniportal video-assisted thoracoscopic lobectomy: two years of experience. Ann Thorac Surg 2013;95:426-32.

2. Chiappetta M, Nachira D, Congedo MT, et al. The surgical technique for cysts removal in uniportal VATS. Asvide 2019;6:321. Available online: http://www.asvide. com/watch/33006

3. Mubang R, Brady JJ, Mao M, et al. Intradiaphragmatic bronchogenic cysts: case report and systematic review. J Cardiothorac Surg 2016;11:79.

4. Taira N, Kawasaki H, Atsumi E, et al. Mucoepidermoid carcinoma of arising from a bronchogenic cyst of the diaphragm. Ann Thorac Cardiovasc Surg 2018;24:247-50.

5. Peng MJ, Wang NS, Vargas FS, et al. Subclinical surface alterations of human pleura. A scanning electron microscopic study. Chest 1994;106:351-3.

6. Wang NS. The preformed stomas connecting the pleural cavity and the lymphatics in the parietal pleura. Am Rev Respir Dis 1975;111:12-20.

7. Claude-Desroches M, Bierry G, Touitou-Gottenberg D, et al. Focal dependent pleural thickening at MDCT: pleural lesion or functional abnormality? Diagn Interv Imaging 2012;93:360-4.

doi: $10.21037 /$ shc.2019.11.04

Cite this article as: Chiappetta $M$, Nachira D, Congedo MT, Ferretti GM, Iaffaldano A, Ciavarella LP, Meacci M, Margaritora S. An uncommon presentation of cystic pachypleuritis successfully treated by uniportal VATS-case report. Shanghai Chest 2019;3:62. 